\title{
Capturing structural changes of photosystem II using time-resolved serial femtosecond crystallography with proper flash excitations
}

Honjie Li

Okayama University https://orcid.org/0000-0002-8827-0093

\section{Yoshiki Nakajima}

Research Institute for Interdisciplinary Science and Graduate School of Natural Science and Technology, Okayama University https://orcid.org/0000-0002-0529-8075

Takashi Nomura

University of Hyogo

Michihiro Sugahara

RIKEN

Shinichiro Yonekura

Okayama University

Siu Kit Chan

Okayama University

Takanori Nakane

MRC laboratory of molecular biology https://orcid.org/0000-0003-2697-2767

Takahiro Yamane

Okayama University

Yasufumi Umena

Okayama University

Mamoru Suzuki

Osaka University

Tetsuya Masuda

Kyoto University

Taiki Motomura

Okayama university

Hisashi Naitow

RIKEN SPring-8 Center https://orcid.org/0000-0001-7567-231X

\section{Yoshinori Matsuura}

RIKEN SPring-8 Center

\section{Tetsunari Kimura}

Kobe University 


\section{Kensuke Tono}

Japan Synchrotron Radiation Research Institute

\section{Shigeki Owada}

RIKEN

Yasumasa Joti

RIKEN SPring-8 Center

\section{Rie Tanaka}

RIKEN SPring-8 Center

\section{Eriko Nango}

Tohoku University

\section{Fusamichi Akita}

Okayama University https://orcid.org/0000-0003-0537-6157

\section{Minoru Kubo}

University of Hyogo https://orcid.org/0000-0002-1470-942X

\section{So Iwata}

Kyoto University https://orcid.org/0000-0003-1735-2937

\section{Jian-Ren Shen}

Okayama University https://orcid.org/0000-0003-4471-8797

\section{Michihiro Suga ( $\square$ msuga@okayama-u.ac.jp )}

Okayama university https://orcid.org/0000-0001-8542-5910

\section{Article}

Keywords: photosystem II, PSII, serial femtosecond crystallography, TR-SFX, water-splitting reaction

Posted Date: July 30th, 2020

DOI: https://doi.org/10.21203/rs.3.rs-41101/v1

License: (c) (1) This work is licensed under a Creative Commons Attribution 4.0 International License. Read Full License 


\section{Abstract}

Photosystem II (PSII) catalyzes light-induced water oxidation through an Si-state cycle, leading to the generation of di-oxygen, protons, and electrons. Pump-probe time-resolved serial femtosecond crystallography (TR-SFX) has been used to capture intermediate states of light-driven enzymatic reactions. In this approach, it is crucial to avoid contamination of light into the samples when analyzing a particular reaction intermediate. Here, we describe a method for determining a proper light condition that avoids light contamination to the PSII microcrystals while minimizing the sample consumption in TRSFX. With the proper illumination conditions determined, we analyzed the S2-state structure of PSII at room temperature, revealing the structural changes during the S1-to-S2 transition at an ambient temperature. By comparing with the previous studies performed at a low temperature or with a different delay time, we reveal the possible channels for water inlet and proton egress, as well as structural changes important for the water-splitting reaction.

\section{Introduction}

Oxygenic photosynthesis converts light energy into chemical energy, thereby sustaining all aerobic life on Earth. The energy-conversion reaction of photosynthesis is carried out by two photosystems (PSs), PSI and PSII, both are large membrane-embedded protein-pigment complexes existing on the thylakoid membranes of plants and various algae. Among these two PSs, PSIl uses light energy to extract electrons and protons from water molecules, leading to the oxidation of water and release of dioxygen as a byproduct. This water oxidation reaction is catalyzed by the oxygen-evolving complex (OEC) of PSII and proceeds through a light-driven, five-step $S_{i}$-state cycle $(i=0-4)^{1-4}$ (Fig. 1a). In this $S_{i}$-state cycle, $S_{0}$ is the ground state, and the OEC progresses to higher $\mathrm{S}_{i}$ states upon its oxidation by $\mathrm{Y}_{Z}{ }^{+}$, a tyrosine cation residue generated by $\mathrm{P}_{680}{ }^{+}$, the photoexcited PSIl reaction center $\mathrm{P}_{680}$ (Fig. 1b). Dioxygen is released during the $S_{3}{ }^{\circledR}\left(S_{4}\right) \circledast S_{0}$ transition. The OEC in the $S_{1}$ state is dark-stable, and its structure has been determined to have a chemical composition of $\mathrm{Mn}_{4} \mathrm{CaO}_{5}{ }^{5,6}$. This structure changes to a $\mathrm{Mn}_{4} \mathrm{CaO}_{6}$-cluster in the highest metastable $S_{3}$ state by incorporation of a new oxygen atom $\left(06^{7,8}\right.$ or $\left.0 x^{9}\right)$ near the unique $\mu$-oxo bridge 05. The interatomic distance between 06 and 05 is $1.9-2.0 \AA$ in the $S_{3}$ state ${ }^{8,9}$, which is suitable for an oxyl/oxo type coupling to form dioxygen between them. The detailed mechanism of the water oxidation, however, has not been well understood, in particular with respect to the origin of 06 and the proton exit pathways.

Since the $\mathrm{Mn}_{4} \mathrm{CaO}_{5}$ cluster is embedded inside the protein matrix of PSII and covered by a large area of hydrophilic protein regions in the lumenal side of the thylakoid membrane, channels for the inlet of substrate waters and egress of the product protons are important for the water-splitting reaction to proceed properly. The high resolution structure of PSII showed multiple hydrogen-bond networks connecting the site of the $\mathrm{Mn}_{4} \mathrm{CaO}_{5}$ cluster to the lumenal surface of PSIl complex ${ }^{1,5,6}$ these channels may therefore function to allow water coming into the catalytic site or protons to be transported to the 
lumenal solution. Four main such channels have been identified; they are designated 01-channel, 04channel, Cl1-channel, and Cl2-channel (Fig. 1). The 01-and 04-channels are so called because they start from the oxo-bridge 01 and 04 of the $\mathrm{Mn}_{4} \mathrm{CaO}_{5}$ cluster, respectively, whereas the $\mathrm{Cl} 1$ - and $\mathrm{Cl} 2$-channels are mediated by the $\mathrm{Cl} 1$ and $\mathrm{Cl} 2$ ions in the vicinity of the $\mathrm{Mn}_{4} \mathrm{CaO}_{5}$ cluster, respectively. It is not clear which of these channels functions in the water inlet or proton egress, and in the latter case, in which Sstate transition.

Pump-probe, time-resolved serial femtosecond X-ray crystallography (TR-SFX) using X-ray free-electron lasers (XFEL) is a powerful method to visualize structural dynamics of light-triggered enzymes ${ }^{10-15}$, including PSII in different $S_{i}$-states at an ambient temperature ${ }^{7,9,16}$. XFELs are femtosecond pulses of $X$ ray with billions of times brilliance than that of conventional synchrotron X-rays, thus enabling collection of the diffraction data before the onset of radiation damage ${ }^{17}$. For trapping the intermediate $\mathrm{S}_{\mathrm{i}}$-states of PSIl with this method, a flow of PSII microcrystals is illuminated by a desired number of pump flashes to generate the higher $\mathrm{S}_{5}$-states (one, two, or three flashes generate $\mathrm{S}_{2}, \mathrm{~S}_{3}$, or $\mathrm{S}_{0}$ states, respectively), followed by detection with an XFEL pulse with a temporal delay time after the flash illumination. One of the most critical factors for the success of this experiment is the selection of an optimal light excitation condition (intervals, the boundary of excitation region, and power of the excitation laser, etc.) under particular sample delivery conditions (crystal size, flow diameter, flow rate, overall sample consumption, etc.). A generally applicable way to determine a proper light excitation condition is adding a generous safety margin in the sample area to be excited and examining the structural changes by the TR-SFX experiment under a suitable size and power of the pump laser illumination. In the case of enzymes such as PSIl that requires multi-flash excitations for the latter S states, however, the application of this method is not straightforward under the continuous sample flow condition, because the sample area that can be used for the excitation and X-ray diffraction data collection must be well aligned spatially and temporally, and a larger separation between two consecutive flashes may make the illuminated sample to escape from the area that can be irradiated by the XFEL pulses. Thus, higher $S_{i}$ states may not be captured by the TR-SFX method if a too large separation is used between consecutive flashes.

In the present study, we show a method to determine an optimal light illumination condition for successful TR-SFX to analyze the structures of the intermediate $\mathrm{S}_{\mathrm{i}}$-states of PSII. By altering the flash interval distance with a maximum delay time and examining the structural changes that occurs during the $S_{1}$-to- $S_{2}$ transition, a boundary of the excitation region was accurately determined. Based on the light illumination conditions determined, we analyzed the PSII structure in the $S_{2}$ state at a 2.4-A resolution. Structural changes were found in the OEC, the 01- and 04-channels, and the $\mathrm{Q}_{B}$-binding site, providing important insights into the proton transfer and substrate water delivery during the water oxidation reaction.

\section{Determination of a boundary of the excitation region in TR-SFX}


We performed TR-SFX as described previously ${ }^{7,18}$. In this approach, PSII microcrystals were mixed with a grease matrix and ejected from a micro-extrusion injector. The flow of the PSII microcrystals were excited by a single flash to advance the S-state to $S_{2}$. Fig. 2a shows a scheme representing the interaction between the pump excitation region and the XFEL pulse in the TR-SFX experiment with a delay time $(\Delta t)$ of $10 \mathrm{~ms}$ at the pump and XFEL repetition rates of $30 \mathrm{~Hz}$. It should be noted that, although the pump beam was focused on the sample stream with a top-hat shape $(\varnothing 250 \mu \mathrm{m})^{19}$, the effective excitation region extended upstream due to the pump-light scattering on the stream. Thus, the excitation region is schematically depicted by a triangle in the figure, indicating a gradual decrease in the pump photon density along the sample stream. When a flow rate is not fast enough for the sample exchange, the pump excitation region interacts with the next pump-XFEL pulse pair (Fig. 2b). To avoid such erroneous lightcontamination, we here designed a test experiment with $\Delta t$ of minus $50 \mathrm{~ns}$, where XFEL pulses were delivered to the microcrystals about $100 \mathrm{~ms}$ (99.99995 ms) after the pump illumination (Fig. 2c). On this negative $\Delta t$ condition, if the flow rate is slow, the microcrystals would be illuminated partially by the preceding flash, resulting in "one-flash" illumination (Fig. 2d). However, at a sufficiently fast flow rate, the microcrystals at the position of the XFEL shot will escape from the preceding flash illumination (Fig. 2e), resulting in a "dark dataset". Accordingly, we can check light-contamination, including an effect of pump light scattering on the sample stream, under the given experimental conditions (pump-illumination size and intensity, sample flow rate, etc).

Four diffraction datasets were collected at different flow rates of $4.9 \mu \mathrm{l} / \mathrm{m}, 7.3 \mu \mathrm{l} / \mathrm{m}, 8.5 \mu \mathrm{l} / \mathrm{m}$ and 9.8 $\mu \mathrm{l} / \mathrm{m}$ (corresponding to 2.0 times, 3.0 times, 3.5 times, and 4.0 times of that for the dark datasets), respectively. In addition to these four datasets, we collected two independent dark datasets from different preparations (Dark1 for the light-illuminated, flow rate $4.9 \mu \mathrm{l} / \mathrm{m}$ and $7.3 \mu \mathrm{l} / \mathrm{m}$ experiments, and Dark2 for the light-illuminated, flow rate $8.5 \mu \mathrm{l} / \mathrm{m}$ and $9.8 \mu \mathrm{l} / \mathrm{m}$ experiments) at a flow rate of $2.5 \mu \mathrm{l} / \mathrm{m}$, and a light dataset with $\Delta t$ of $10 \mathrm{~ms}$ at a flow rate of $9.8 \mu \mathrm{l} / \mathrm{m}$. All datasets were processed at 2.35 to $2.40-\AA$ resolutions (Table 1).

We evaluated the boundary of the excitation region as follows (Methods). Isomorphous difference Fourier maps between the "light"-illuminated and dark datasets were calculated with the phases obtained by the refinement, which showed a negative peak covering W665, the second water molecule from 04 in the 04channel (Fig. 1C, d). Since a similar negative peak has been observed in the previous studies, indicating that W665 becomes highly disordered during the $\mathrm{S}_{1}$-to- $\mathrm{S}_{2}$ transition $^{7-9}$, we take the height of the Fourier difference peak of W665 as an indicator for the light-induced structural changes. The $F_{\text {obs }}(-50$ ns, "light" at $4.9 \mu \mathrm{l} / \mathrm{m}$ ) minus $F_{\text {obs }}$ (dark) difference Fourier map showed a sharp peak height of $-6.4 \sigma$ at the position of W665 (Fig. 3a). This peak height is lower than that observed with a delay time of $10 \mathrm{~ms}$ after the excitation flash (Fig. 3e), but apparently higher than the maximum noise level (Fig. 3f), suggesting that at this flow rate, the microcrystals at the target position of the XFEL shot has been excited by the preceding flash illumination. Thus, the flow rate of $4.9 \mu \mathrm{l} / \mathrm{m}$ is too slow to avoid the light-contamination by the preceding flash in the excitation region. The average height of the light-minus-dark Fourier difference peak of W665 in two non-crystallographic symmetry-related PSII monomers was reduced when the flow 
rate was increased (Fig. $3 b-d$ ), and reached to a level not visible in the difference map contoured at $\pm 4.0 \sigma$ at the flow rate of $9.8 \mu \mathrm{l} / \mathrm{m}$ (Fig. 3d), which is also well below the maximum noise level (Fig. 3f). This indicates that at the flow rate of $9.8 \mu \mathrm{l} / \mathrm{m}$, no apparent light-minus-dark Fourier difference peak was observed. Therefore, we concluded that the flow rate of $9.8 \mu \mathrm{l} / \mathrm{m}$ gives rise to no light-contamination at the position of the XFEL shot. Therefore, we collected the light-illuminated dataset with a $\Delta t$ of $10 \mathrm{~ms}$ after the flash illumination at this flow rate to analyze the PSII structure in the $\mathrm{S}_{2}$ state.

\section{Structural determination of PSII in the $S_{2}$ state}

The $F_{\text {obs }}(10 \mathrm{~ms}$, light, $9.8 \mu \mathrm{l} / \mathrm{m})$ minus $F_{\text {obs }}$ (dark) isomorphous difference Fourier map showed a strong signal with a peak height above $-11.3 \sigma$ at the position of W665, suggesting that the microcrystals were successfully excited to progress to the $\mathrm{S}_{2}$ state (Fig. 3e, f). Many peaks can be seen in the Fourier difference map when we decrease the contour level below $\pm 3 \sigma$; thus we consider that the average noise level is at around $\pm 3 \sigma$, and peaks above $\pm 3 \sigma$ may represent real structural changes induced by one-flash illumination. Most of the peaks that are related to the light-induced structural changes were above $\pm 4.5 \sigma$ and distributed around the electron transfer chain (the OEC, bicarbonate (BCT), non-heme iron, and $\mathrm{Q}_{\mathrm{B}}$ ), and were observed similarly in both PSII monomers. However, some weaker peaks at around $\pm 4 \sigma$ were found at one side of the monomer-monomer interface (Fig. 3g). These weaker peaks may not be related with the light-induced structural changes, and possibly induced by a relatively low isomorphism between the two datasets. These may arise from differences in the batches of samples used, since it was difficult to control the sample purification conditions and sample states, such as dehydration of the crystals, to an entirely uniform one. Nevertheless, we were able to distinguish the essential, light-induced structural changes during the catalytic reaction from the ones associated with the differences in the samples employed based on their peak intensities.

We refined the $10 \mathrm{~ms}$ light dataset as a mixture model consisting of $70 \% \mathrm{~S}_{2}$ state and $30 \% \mathrm{~S}_{1}$ state for the $\mathrm{Mn}_{4} \mathrm{CaO}_{5}$-cluster and the nearby residues (Method). This gives rise to equivalent values of the temperature factors between the two equivalent atoms in the multiple model, and this population of $S_{2}$ and $\mathrm{S}_{1}$-states after one-flash illumination is similar to the efficiencies of the $\mathrm{S}_{\Gamma}$-state transition estimated by the Fourier transform infrared spectroscophy ${ }^{7,20}$. The OEC structures in the $S_{1}$ and $S_{2}$ states determined in the present study are similar to those reported in the previous studies ${ }^{8,9}$. The OEC structure in the $S_{2}$ state was in the open-cubane form, in which the right side of the 05 is open, giving rise to the five-coordinate trigonal bipyramidal coordination of $\mathrm{Mn} 1$. All changes in the $\mathrm{Mn}-\mathrm{Mn}$ and $\mathrm{Mn}$-Ca distances during the $S_{1}$-to- $S_{2}$ transition were less than the error range of the coordinates at the current resolution (Fig. 4). However, the changes found in the isomorphous difference Fourier map, such as the shorting of Mn3-Mn4 and elongations of Mn1-Mn3, Mn3-Ca, and Mn4-Ca, were consistent with the previous study with the diffraction data collected at $100 \mathrm{~K}$ for the room temperature-trapped $\mathrm{S}_{2}$-state ${ }^{8}$ (Fig. 4 and Table 2). In association with the movements of these manganese atoms, some ligand residues of the OEC (D1E189, E333, D342, A344, and CP43-E354) also moved slightly (Fig. 5b). 


\section{Structural changes in the 04 and 01 channels}

Among the four channels, the 04-channel has been suggested to function as the pathway of proton release during the $\mathrm{S}_{0}-$ to- $\mathrm{S}_{1}$ transition based on theoretical calculations ${ }^{21}$. On the other hand, other groups argued that it serves as the source of substrate water by a "pivot" or "carousel" mechanism in the transition of $S_{2}$-to- $S_{3}{ }^{22-24}$. As described above, upon transition to the $S_{2}$ state, W665 in the 04-channel became highly disordered. This is accompanied by slight shifts of the nearby residues D1-D61 and CP43E354 toward the position of W665, resulting in a narrowing of the space that has been occupied by W665 (Figs. 3e and 5b). A water cluster (W546, W548, W612, W606, and W806) leading to the lumenal surface in the 04-channel also shifted their positions during the $\mathrm{S}_{1}$-to- $\mathrm{S}_{2}$ transition, and the shift of W548 induced structural changes of its H-bond partners R334 and N335 (Fig. 5a). These changes in the 04-channel were similar to the previous study analyzed at the cryogenic temperature ${ }^{8}$. However, another water molecule, W757, connected to W548 and W606 in this channel, was found to become disordered in the $\mathrm{S}_{1}$-to- $\mathrm{S}_{2}$ transition at the cryogenic temperature ${ }^{8}$, but this water molecule was not detected in both the $\mathrm{S}_{1}$ and $S_{2}$ structures in the present study, presumably due to its peripheral location and thus weaker association within the channel, resulting in a higher mobility at room temperature at which the TR-SFX experiments were conducted in the present study.

Another noticeable change observed near the OEC was a negative peak of $-7.4 \sigma$ covering W601, the $\mathrm{H}$ bond donor to 01 and one of the members of a diamond-shaped water cluster in the 01-channel (Fig. 5b). This indicates that W601 became disordered in the $\mathrm{S}_{1}-\mathrm{to}-\mathrm{S}_{2}$ transition. This change was not found in our previous study performed at the cryogenic temperature ${ }^{8}$. Another SFX study at ambient temperature by Kern et al. reported the shifts of three water molecules W601, W547, and W536 (W26, W27, and W30) ${ }^{9}$ of the diamond-shaped water cluster. In contrast, our previous fixed-target SFX study at cryogenic temperature reported W571, a water molecule found at a cryogenic temperature only, became disordered instead of $\mathrm{W} 61^{8}$. These differences indicate a high mobility of the water molecules in the 01-channel during the $S_{1}$-to- $S_{2}$ transition. Such an increase of the mobility during the $S_{1}$-to- $S_{2}$ transition at room temperature may be necessary to allow incorporation of the substrate water molecule(s) into the OEC during the $S_{2}$-to- $S_{3}$ transition, which in turn suggests that the 01-channel may be responsible for the substrate water to enter into the reaction site.

\section{$\mathrm{Q}_{B}$ and the non-heme iron site}

After one flash illumination, the second bound quinone electron acceptor $Q_{B}$ undergoes reduction and protonation to form a stable plastosemiquinone intermediate $\mathrm{Q}_{B} \mathrm{H}^{*}$. The isomorphous difference Fourier map showed a positive peak covering the $Q_{B}$ head and a pair of positive and negative peaks over the $Q_{B}$ tail, suggesting its slight movement during the $S_{1}$-to- $S_{2}$ transition (Fig. 5c). The B-factor of the $Q_{B}$ head was decreased from $121 \AA^{2}$ in the $S_{1}$-state to $103 \AA^{2}$ in the $S_{2}$-state, and the $\mathrm{H}$-bond length between the head of $\mathrm{Q}_{\mathrm{B}}$ and $\mathrm{S} 264$ was also changed from $2.92 \AA$ in the $\mathrm{S}_{1}$-state to $2.77 \AA$ in the $\mathrm{S}_{2}$-state, indicating a 
tighter binding of $\mathrm{Q}_{B} \mathrm{H}^{\cdot}$ to $\mathrm{S} 264$. Thus, the first protonation of $\mathrm{Q}_{B}$ may occur at this site. This notion is consistent with the theoretical calculation that the first proton transfer from $S 264$ to $Q_{B}$ is an energetically downhill process, whereas it is an uphill one from $\mathrm{H} 215$ to $\mathrm{Q}_{B}{ }^{25}$. Several pairs of positive and negative peaks were also found around the H-bond network formed by the bicarbonate (BCT), D1-Y246, D1-E244, D2-K264, and D2-E242, and BCT moved $0.39 \AA$ away from the non-heme iron (Fig. 5c). These changes may be related to the reduction of the non-heme iron or proton uptake after one flash illumination, which in turn suggests that these residues form part of the proton inlet channel for the protonation of $Q_{B}$.

\section{Discussions}

For the success of the pump-probe TR-SFX experiments to analyze intermediate structures of enzymes using light as the pump to initiate the reaction, it is critical to find an optimal light excitation condition with an optimal sample delivery system. These conditions vary considerably depending on the sample of interests as well as the setup of the pump-probe SFX system. Under optimal conditions, one can save a large amount of the valuable protein samples as well as the XFEL beamtime to obtain structures of the targeted intermediate states. In the present study, we showed a method to determine a boundary excited by the pump by altering the flow rate of the microcrystals and evaluating the resulted light-induced structural changes of PSII. With the optimal conditions obtained, we analyzed the structure of PSII in the $\mathrm{S}_{2}$ state at room temperature by the TR-SFX method. This method can apply to other samples whose catalytic reaction are triggered by light, by using systems which deliver microcrystals in a continuous flow. Importantly, this method also provides a suitable light condition for samples, such as PSII, that require successive flash excitations for its catalytic cycle.

The PSIl structures in the $\mathrm{S}_{1}$ and $\mathrm{S}_{2}$ states, as well as the isomorphous difference Fourier map obtained in the present study, revealed the light-induced structural changes localized at the $O E C, Q_{B}$ site, and water molecules in the 01 and 04 channels. Comparison of the changes observed at the ambient temperature with a $\Delta t$ of 10 ms obtained in the present study, with the previous study where the $\mathrm{S}_{2}$-state was trapped cryogenically with a $\Delta t$ of around one $s$ and the diffraction data collected at a low temperature ${ }^{8}$, as well as that carried out at the ambient temperature with a $\Delta t$ of $200 \mathrm{~ms}^{9}$, shows an overall tendency of the structural changes. The changes found in the OEC were identical regardless of the ambient/cryogenic temperatures or the different $\Delta t$, suggesting the stability and the long lifetime of the catalytic center in the $\mathrm{S}_{2}$-state. By contrast, the changes found in some amino acid residues and water molecules differ substantially either depending on the temperatures or $\Delta t$, reflecting a rather large mobility of the protein environment. This tendency is apparent in the $Q_{B}$ site, in which the quinone changes its redox forms during the catalytic cycle. The changes in the $\mathrm{Q}_{B}$ site were larger with the $\Delta t$ of $10 \mathrm{~ms}$ but smaller with the $\Delta t$ of $200 \mathrm{~ms}^{9}$ and further diminished at the $\Delta t$ of around one $\mathrm{s}^{8}$.

Comparisons of the structural changes in the 01 and 04-channels with the previous crystallographic studies $^{8,9}$ also reveal the characteristic properties of the water molecules. W665, the second water from 
04 in the 04-channel, became highly mobile in the $S_{1}$-to- $S_{2}$ transition, which is consistent with the previous studies. The disorder of $\mathrm{W} 665$ breaks the $\mathrm{H}$-bond network in the 04-channel in the $\mathrm{S}_{2}$-state. In our initial report of the disorder of W665 in the $\mathrm{S}_{2}$-state, we proposed that proton transfer may occur in the 04-channel in the $\mathrm{S}_{1}$-to- $\mathrm{S}_{2}$ transition $^{8}$. The changes observed in the 04-channel were similar to the theoretical calculation that reported a proton release in the channel in the $S_{0}$-to- $S_{1}$ transition ${ }^{21}$. However, FTIR studies on D1-S169A mutant, which perturbs the interaction of a water molecule hydrogen-bonded with 04 , showed only minor effects on the efficiencies or kinetics of the Si-state transitions ${ }^{26,27}$. In contrast, the $\mathrm{S}_{2}$-state multiline EPR spectrum of the D1-S169A mutant differs significantly from that of wild-type ${ }^{27}$. A further theoretical study on the 04-channel showed that the removal of water molecules in the 04-channel results in a decrease in the $\mathrm{S}_{2} / \mathrm{S}_{1}$ redox potential by $\sim 80 \mathrm{mV}^{28}$. Therefore, the weakened $\mathrm{H}$-bond network due to the increased mobility of W665 may be necessary for the decrease in the redox potential to facilitate the $\mathrm{S}_{1}$-to- $\mathrm{S}_{2}$ transition.

In contrast to the changes observed in the 04-channel, the changes in the water molecules of the 01channel differ between the present and previous studies. W601, the $\mathrm{H}$-bond donor to 01, became disordered in the present study at a $\Delta t$ of $10 \mathrm{~ms}$, and two additional water molecules W547 and W536 (W26, W27, and W29) ${ }^{9}$ became disordered at a $\Delta t$ of $200 \mathrm{~ms}$. However, instead of these water molecules, W571 became disordered in the study with a $\Delta t$ of around one $\mathrm{s}$ at the cryogenic temperature ${ }^{8}$. Because the 01-channel is a broad channel where water molecules are the major component of the $\mathrm{H}$-bond network, substrate water molecules likely propagate through the waters in the 01-channel. Increasing the mobility of waters in this channel may be of benefit in driving the incorporation of the substrate water into the catalytic site in the following $S_{3}$ state.

Fig. 6 summarizes the structural changes regarding the water molecules in the 01 and 04-channels observed in the present study. In the $\mathrm{S}_{1}$-to- $\mathrm{S}_{2}$ transition, W665 in the 04-channel becomes highly mobile, disconnecting the 15-Å long water chain starting from 04-W567. W665 remains disordered in the $S_{3}$ state but becomes re-ordered beyond the $S_{3}$ state $^{8,9}$. W601 in the 01-channel also becomes disordered in the $\mathrm{S}_{1}$-to- $\mathrm{S}_{2}$ transition. The mobility of W601 is propagated to W547, W536, and W571 through the H-bond network in the 01-channel. D1-E189, the only monodentate carboxyl ligand of the OEC, flips by 0.5-Å in the following $S_{2}$-to- $S_{3}$ transition, leading to the broadening of the 01-channel, thereby further increases the mobility of water molecules there ${ }^{7-9}$. The flipping of D1-E189 makes a space in the vicinity of 05 to allow the insertion of the additional water (oxygen) 06 in the subsequent $S_{2}$-to- $S_{3}$ transition. This suggests that waters in the 01-channel may be the source for 06. Dioxygen is then likely formed between 05 and 06 , or between 05 and another water molecule, by an oxyl/oxo coupling mechanism, and in the latter case, 06 refills the empty substrate site. The changes of waters in the 01-channel support the mechanism of water delivery from the Ca side ${ }^{8,29,30}$, rather than the 04-channel ${ }^{22-24}$. Further structural analysis will be required to reveal how the OEC incorporates those waters in the 01-channel and how protons egress during the subsequent S-state transitions. 


\section{Methods}

\section{Preparation and crystallization of photosystem II.}

Highly active dimeric PSII core complexes were purified from the thermophilic cyanobacterium Thermosynechococcus vulcanus cells and crystallized as described previously ${ }^{6,7}$. The microcrystals grew to a maximum size of $100 \mu \mathrm{m}$ and showed a good quality in diffraction as well as a high efficiency in the progress of the $S_{i}$-state cycle. Prior to the TR-SFX experiments, the microcrystals were pre-flashed by a Nd:YAG laser at $532 \mathrm{~nm}$ with a diameter of $7 \mathrm{~mm}$ at an energy of around $52 \mathrm{~mJ} / \mathrm{cm}^{7}$, to oxidize the tyrosine $D$ residue (D2-Y160) and decrease the contamination of the $S_{0}$ state. Then the microcrystals were dehydrated with a buffer containing 20\% glycerol, 10\% PEG 1,450, 10\% PEG 5,000 MME, 2\% dimethyl sulfoxide, and $10 \mathrm{mM}$ potassium ferricyanide in the crystallization buffer by stepwise replacement of the solution, which took around two hours. Following the dehydration, the crystals were mixed with a silicon grease ${ }^{18}$ and used for the TR-SFX experiments. All the procedures, including purification, crystallization, pre-flash illumination, dehydration, and mixing with the grease matrix, were performed in the dark or under dim green light.

\section{Diffraction experiments at SACLA-XFEL.}

The PSII crystals mixed with the grease matrix were loaded into an injector ${ }^{31}$ with a nozzle diameter of $140 \mu \mathrm{m}$ and set in a pump-probe system based on Diverse Application Platform for Hard X-ray Diffraction in SPring-8 Angstrom Compact Free Electron Laser (SACLA) (DAPHNIS) ${ }^{19,32}$. The flow rates were set as follows: $2.5 \mu \mathrm{l} / \mathrm{m}$ for the dark datasets; $4.9 \mu \mathrm{l} / \mathrm{m}, 7.3 \mu \mathrm{l} / \mathrm{m}, 8.5 \mu \mathrm{l} / \mathrm{m}$, and $9.8 \mu \mathrm{l} / \mathrm{m}$, for each "light" dataset at a delay time of $-50 \mathrm{~ns} ; 9.8 \mu \mathrm{l} / \mathrm{m}$ for the light dataset at a delay time of $10 \mathrm{~ms}$. As the pump laser, a 532 $\mathrm{nm}$ pulse from Nd:YAG laser source (Minilite-l, Continuum) with a repetition of $10 \mathrm{~Hz}$ was split into two beams, and each beam was focused on the microcrystals from two different directions with an angle of $160^{\circ}$ to ensure sufficient excitation ${ }^{7}$. The pump focal diameter was set to $240 \mu \mathrm{m}$ at the targeted sample position, and its energy was $42 \mathrm{~mJ} / \mathrm{cm}^{2}$ from each direction. Diffraction images were collected using femtosecond X-ray pulses from SACLA at BL3 with the following pulse parameters: pulse duration, 2-10 fs; $X$-ray energy, $7 \mathrm{keV}$; energy bandwidth, $0.5 \%$ (FWHM); pulse flux, $7 \times 10^{10}$ photons per pulse; beam size $3.0 \mu \mathrm{m}(\mathrm{H}) \times 3.0 \mu \mathrm{m}(\mathrm{W})$; repetition rate, $30 \mathrm{~Hz}$. The XFEL pulses were provided to the pump focal center either before $50 \mathrm{~ns}$ of the pump laser pulse for the "light" datasets at different flow rates, or 106 $\mu \mathrm{m}$ downstream from the pump focal center after $10 \mathrm{~ms}$ of the pump laser pulse for the light dataset that transform the $\mathrm{S}$ state fully to the $\mathrm{S}_{2}$ state. Diffraction images were recorded by a multiport CCD detector. Because the excitation laser pulses were provided at $10 \mathrm{~Hz}$ and the XFEL pulses had a repetition rate of $30 \mathrm{~Hz}$, each "pump-on" images were recorded at $10 \mathrm{~Hz}$ for the "light" datasets, whereas the diffraction data for the dark dataset were recorded at $30 \mathrm{~Hz}$ in a separate run.

\section{Data processing.}


The diffraction data collected at SACLA was monitored by the program cheetah ${ }^{33,34}$, and the diffraction images passing through the "filter" with pre-defined thresholds of diffraction spot numbers (recorded as "hit") were used for the subsequent processing. Indexing, integration, scaling, and merging of the images were carried out by programs in the cctbx.xfe/ suite ${ }^{35,36,37}$. The diffraction images were indexed and integrated by the program dials.stills_process using the geometry of the detector and a camera distance refined by the program cspad.cbf_metrology. The unit cell parameters $(a=126.28, b=232.13, c=289.03$, and $a=\beta=\gamma=90^{\circ}$ ), which was originally determined by the program CrystFEL ${ }^{38}$ was provided during the indexing process. The number of indexed images for each dataset were as follows: 96,459 for Dark1; 41,071 for Dark2; 18,216 for -50 ns, "light", $4.9 \mu \mathrm{l} / \mathrm{m}$; 13,858 for $-50 \mathrm{~ns}$, "light", $7.3 \mu \mathrm{l} / \mathrm{m} ; 20,449$ for -50 ns, "light", $8.5 \mu \mathrm{l} / \mathrm{m}$; 22,419 for -50 ns, "light", $9.8 \mu \mathrm{l} / \mathrm{m}$; 17,247 for $10 \mathrm{~ms}$, light, $9.8 \mu \mathrm{l} / \mathrm{m}$, datasets (Table1). Integrated images were merged by the program cxi.merge with the post refinement rs2 algorithm, and a filter based on the value of $I / \sigma(I)$ was not applied to include weak signals at high resolution. Dark 1 or Dark2 was used as the reference model in the processing of the "light" datasets from the same purification. All datasets are processed to 2.35-2.40 $\AA$ resolutions based on the criteria of $\mathrm{CC}_{1 / 2}$ larger than $50 \%$. The $R_{\text {iso }}$ values between the datasets were 0.073 to 0.100 in the same sample batch, and 0.095 to 0.112 between the different sample batches. Because different sample batches gave a slightly higher $R_{\text {iso }}$ between the different datasets and because lower $R_{\text {iso }}$ was crucial to detect meaningful structural changes based on the isomorphous difference Fourier map, we collected the two different dark datasets (Dark1 and Dark2) independently for the different sample bathes used.

\section{Model building and map calculation}

The initial phase of the dark dataset was obtained by molecular replacement with the program Phaser$M R$ in the CCP4 package ${ }^{39}$, using the previous PSIl structure at room temperature (PDB code: $\left.5 \mathrm{ws} 5\right)^{7}$ as the search model. Then, an initial rigid-body refinement, followed by refinement of coordinates, $B$ factors, and TLS, was performed by the program, Phenix ${ }^{40,41}$ combined with manual modifications with the program $\mathrm{Coot}^{42}$. The restraints used here were the same as those used previously 7,8 . The final $R_{\text {factor }}$ and $R_{\text {free }}$ were 0.170 and 0.214 for the Dark1 dataset, and 0.179 and 0.219 for the Dark2 dataset (Table 1). The phases from the refined model of dark1 or dark2 were used to calculate the isomorphous difference Fourier maps between dark and each $-50 \mathrm{~ns}$, "light", datasets or $10 \mathrm{~ms}$, light, dataset. Sharp peaks in the isomorphous difference Fourier maps were localized around the regions of the $\mathrm{OEC}, \mathrm{Q}_{B}$, non-heme iron, and those regions were built as a mixture of dominant $S_{2}$ state and minor $S_{1}$ state based on the transition efficiency of the PSII microcrystals ${ }^{20}$. We first refined coordinates of dominant $\mathrm{S}_{2}$ state only with fixed Bfactors. Then we refined the B-factors of atoms in the regions mentioned above that show structural changes during the $S_{1}$-to- $S_{2}$ transition by assuming the populations of the $S_{2}$ and $S_{1}$ states at $(0.9,0.1)$, $(0.8,0.2),(0.7,0.3)$ and $(0.6,0.4)$, and found that the residual electron densities and B-factors after the refinement was reasonable with the population of $S_{2}$ and $S_{1}$ states of 0.7 and 0.3 , respectively. Thus, this population was used to refine the final structure in the $S_{2}$ state. The statistics for structural refinement were provided in Table 1. 


\section{Declarations}

\section{Data availability}

The structure factors and atomic coordinates have been deposited in the Protein Data Bank (PDB) with accession numbers 7CJI and 7CJJ for the dark2 and $10 \mathrm{~ms}$, light datasets, respectively. All other data associated with this manuscript are available from the authors on a reasonable request.

\section{Acknowledgments}

We thank T. Nakano and S. Goda for growing and harvesting the cyanobacterial cells. This work was supported by JSPS KAKENHI Grants JP17H05884, JP2OH05446, JP20H03226 (M. Suga), JP17H06434 (J.-R. S.), JP19H05784 (M. K.), JP19H05781 (E. N.), and JST, PREST grants JPMJPR18G8 (M. Suga), JPMJPR16P1 (F. A.). S.I.

supported by Platform Project for Supporting Drug Discovery and Life Science Research (Basis for Supporting Innovative Drug Discovery and Life Science Research (BINDS)) from Japan Agency for Medical Research and Development (AMED). The XFEL experiments were performed at beamlines 2 and 3 of SACLA with the approval of the Japan Synchrotron Radiation Research Institute (JASRI) (proposals 2016A8033, 2016B8066, 2017A8041, 2017B8025, 2018A8037, and 2018B8029) and we thank the staff at SACLA for their help. We also acknowledge the computational support from SACLA HPC system and Mini-K supercomputer system.

\section{Author contributions}

J.-R. S. conceived the project; M. Suga, M. K., E. N., and J.-R. S. designed the experiments; Y. N., S. Y., and S. K. C. purified and crystalized PSII; M. Suga, H. L., Y. N., M. Sugah., S. Y., S. K. C., T. Y., Y. U., T. Ma., M. Suz., T. Mo., H. N., Y. M., R. T., F. A., and J.-R. S. participated in the data collection. M. K., T. No., and T. K. designed the pump excitation scheme; K. T., S. O., and Y. J. operated beamline. T. Na., and S. I. Developed the data evaluation and hit finding programs for TR-SFX; T. Na. adapted DIALS for MPCCD datasets. H. L., T. Y., and M. Suga analyzed the X-ray diffraction; L. H., M. Suga, and J.-R. S. wrote the paper with inputs from all authors.

\section{References}

1. Shen JR. The Structure of Photosystem II and the Mechanism of Water Oxidation in Photosynthesis. Annual review of plant biology 66, 23-48 (2015).

2. Cox N, Pantazis DA, Neese F, Lubitz W. Biological water oxidation. Accounts of chemical research 46, 1588-1596 (2013).

3. Yano J, Yachandra V. Mn4Ca cluster in photosynthesis: where and how water is oxidized to dioxygen. Chem Rev 114, 4175-4205 (2014). 
4. Kok BF, B.; McGloin, M.. Cooperation of charges in photosynthetic $\mathrm{O}_{2}$ evolution-I. A linear four step mechanism. Photochem Photobiol 11, 457-475 (1970).

5. Suga $\mathrm{M}$, et al. Native structure of photosystem II at 1.95 angstrom resolution viewed by femtosecond X-ray pulses. Nature 517, 99-U265 (2015).

6. Umena Y, Kawakami K, Shen JR, Kamiya N. Crystal structure of oxygen-evolving photosystem II at a resolution of 1.9 A. Nature 473, 55-60 (2011).

7. Suga $\mathrm{M}$, et al. Light-induced structural changes and the site of $\mathrm{O}=\mathrm{O}$ bond formation in PSIl caught by XFEL. Nature, (2017).

8. Suga $\mathrm{M}$, et al. An oxyl/oxo mechanism for oxygen-oxygen coupling in PSIl revealed by an x-ray freeelectron laser. Science 366, 334-338 (2019).

9. Kern J, et al. Structures of the intermediates of Kok's photosynthetic water oxidation clock. Nature 563, 421-425 (2018).

10. Nango $\mathrm{E}$, et al. A three-dimensional movie of structural changes in bacteriorhodopsin. Science 354 , 1552-1557 (2016).

11. Barends TR, et al. Direct observation of ultrafast collective motions in $\mathrm{CO}$ myoglobin upon ligand dissociation. Science 350, 445-450 (2015).

12. Pande $\mathrm{K}$, et al. Femtosecond structural dynamics drives the trans/cis isomerization in photoactive yellow protein. Science 352, 725-729 (2016).

13. Tenboer $\mathrm{J}$, et al. Time-resolved serial crystallography captures high-resolution intermediates of photoactive yellow protein. Science 346, 1242-1246 (2014).

14. Nogly $\mathrm{P}$, et al. Retinal isomerization in bacteriorhodopsin captured by a femtosecond $\mathrm{x}$-ray laser. Science 361, (2018).

15. Suga M, Shimada A, Akita F, Shen JR, Tosha T, Sugimoto H. Time-resolved studies of metalloproteins using X-ray free electron laser radiation at SACLA. Biochim Biophys Acta Gen Subj 1864, 129466 (2020).

16. Kupitz C, et al. Serial time-resolved crystallography of photosystem II using a femtosecond X-ray laser. Nature, (2014).

17. Neutze R, Wouts R, van der Spoel D, Weckert E, Hajdu J. Potential for biomolecular imaging with femtosecond X-ray pulses. Nature 406, 752-757 (2000).

18. Sugahara $\mathrm{M}$, et al. Grease matrix as a versatile carrier of proteins for serial crystallography. Nature methods 12, 61-63 (2015).

19. Kubo M, et al. Nanosecond pump-probe device for time-resolved serial femtosecond crystallography developed at SACLA. Journal of synchrotron radiation 24, 1086-1091 (2017).

20. Kato Y, et al. Fourier Transform Infrared Analysis of the S-State Cycle of Water Oxidation in the Microcrystals of Photosystem II. J Phys Chem Lett, (2018).

21. Saito K, William Rutherford A, Ishikita $H$. Energetics of proton release on the first oxidation step in the water-oxidizing enzyme. Nature communications 6, 8488 (2015). 
22. Wang J, Askerka M, Brudvig GW, Batista VS. Crystallographic Data Support the Carousel Mechanism of Water Supply to the Oxygen-Evolving Complex of Photosystem II. ACS Energy Letters, 2299-2306 (2017).

23. Retegan $\mathrm{M}$, et al. A five-coordinate Mn(iv) intermediate in biological water oxidation: spectroscopic signature and a pivot mechanism for water binding. Chem Sci 7, 72-84 (2016).

24. Kawashima K, Takaoka T, Kimura H, Saito K, Ishikita H. O2 evolution and recovery of the wateroxidizing enzyme. Nature communications 9, 1247 (2018).

25. Saito K, Rutherford AW, Ishikita H. Mechanism of proton-coupled quinone reduction in Photosystem II. Proceedings of the National Academy of Sciences of the United States of America 110, 954-959 (2013).

26. Shimada Y, Kitajima-Ihara T, Nagao R, Noguchi T. Role of the 04 Channel in Photosynthetic Water Oxidation as Revealed by Fourier Transform Infrared Difference and Time-Resolved Infrared Analysis of the D1-S169A Mutant. The journal of physical chemistry B124, 1470-1480 (2020).

27. Ghosh I, et al. D1-S169A Substitution of Photosystem II Perturbs Water Oxidation. Biochemistry 58, 1379-1387 (2019).

28. Mandal M, Kawashima K, Saito K, Ishikita H. Redox Potential of the Oxygen-Evolving Complex in the Electron Transfer Cascade of Photosystem II. Journal of Physical Chemistry Letters 11, 249-255 (2020).

29. Kim CJ, Debus RJ. One of the Substrate Waters for 02 Formation in Photosystem II Is Provided by the Water-Splitting Mn4CaO5 Cluster's Ca(2+) Ion. Biochemistry 58, 3185-3192 (2019).

30. Sakamoto H, Shimizu T, Nagao R, Noguchi T. Monitoring the Reaction Process During the S2 $\rightarrow$ S3 Transition in Photosynthetic Water Oxidation Using Time-Resolved Infrared Spectroscopy. Journal of the American Chemical Society 139, 2022-2029 (2017).

31. Shimazu Y, et al. High-viscosity sample-injection device for serial femtosecond crystallography at atmospheric pressure. Journal of applied crystallography 52, 1280-1288 (2019).

32. Tono $\mathrm{K}$, et al. Diverse application platform for hard X-ray diffraction in SACLA (DAPHNIS): application to serial protein crystallography using an X-ray free-electron laser. Journal of synchrotron radiation 22, 532-537 (2015).

33. Barty A, et al. Cheetah: software for high-throughput reduction and analysis of serial femtosecond Xray diffraction data. J App/ Crystallogr 47, 1118-1131 (2014).

34. Nakane T, et al. Data processing pipeline for serial femtosecond crystallography at SACLA. Journal of Applied Crystallography 49, 1035-1041 (2016).

35. Sauter NK, Hattne J, Grosse-Kunstleve RW, Echols N. New Python-based methods for data processing. Acta Crystallogr D Biol Crystallogr 69, 1274-1282 (2013).

36. Sauter NK. XFEL diffraction: developing processing methods to optimize data quality. J Synchrotron Radiat 22, 239-248 (2015). 
37. Waterman DG, et al. Diffraction-geometry refinement in the DIALS framework. Acta Crystallogr D Struct Biol 72, 558-575 (2016).

38. White TA, et al. CrystFEL: a software suite for snapshot serial crystallography. Journal of applied crystallography 45, 335-341 (2012).

39. Collaborative Computational Project N. The CCP4 suite: programs for protein crystallography. Acta crystallographica Section D, Biological crystallography 50, 760-763 (1994).

40. Adams PD, et al. PHENIX: a comprehensive Python-based system for macromolecular structure solution. Acta crystallographica Section D, Biological crystallography 66, 213-221 (2010).

41. Afonine PV, et al. Towards automated crystallographic structure refinement with phenix.refine. Acta Crystallogr D Biol Crystallogr 68, 352-367 (2012).

42. Emsley P, Cowtan K. Coot: model-building tools for molecular graphics. Acta crystallographica Section D, Biological crystallography 60, 2126-2132 (2004).

\section{Tables}

Table 1 Statistics for data collection and structural refinement. 


\begin{tabular}{|c|c|c|c|c|c|c|c|}
\hline Data name & Dark1 & Dark2 & $\begin{array}{l}-50 \mathrm{~ns}, \\
\text { "light", } \\
4.9 \mu \mathrm{l} / \mathrm{m}\end{array}$ & $\begin{array}{l}-50 \mathrm{~ns}, \\
\text { "light", } \\
7.3 \mu \mathrm{l} / \mathrm{m}\end{array}$ & $\begin{array}{l}-50 \mathrm{~ns}, \\
\text { "light" } \\
8.5 \mu \mathrm{l} / \mathrm{m}\end{array}$ & $\begin{array}{l}-50 \mathrm{~ns}, \\
\text { "light", } \\
9.8 \mu \mathrm{l} / \mathrm{m}\end{array}$ & $\begin{array}{l}10 \mathrm{~ms} \text {, } \\
\text { light, } \\
9.8 \mu \mathrm{l} / \mathrm{m}\end{array}$ \\
\hline \multicolumn{8}{|l|}{ Data collection } \\
\hline $\begin{array}{l}\text { Flow rate }(\mu \mathrm{l} \\
/ \mathrm{m})\end{array}$ & 2.5 & 2.5 & 4.9 & 7.3 & 8.5 & 9.8 & 9.8 \\
\hline $\begin{array}{l}\text { No. of indexed } \\
\text { images }\end{array}$ & 96,459 & 41,071 & 18,216 & 13,858 & 20,449 & 22,419 & 17,247 \\
\hline Space group & $P 2_{1} 2_{1} 2_{1}$ & & & & & & \\
\hline Unit cell $(\AA ̊)$ & $\begin{array}{l}a=126.1, \\
b=231.7, \\
c=288.3\end{array}$ & $\begin{array}{l}a=126.0, \\
b=231.7, \\
c=288.3\end{array}$ & $\begin{array}{l}a=125.8, \\
b=231.5, \\
c=288.2\end{array}$ & $\begin{array}{l}a=126.0, \\
b=231.6, \\
c=288.2\end{array}$ & $\begin{array}{l}a=125.7 \\
b=231.6 \\
c=288.4\end{array}$ & $\begin{array}{l}a=125.6, \\
b=231.7, \\
c=288.5\end{array}$ & $\begin{array}{l}a=125.7, \\
b=231.5, \\
c=288.3\end{array}$ \\
\hline Resolution $(\AA)$ & $40-2.40$ & $40-2.35$ & $40-2.40$ & $40-2.40$ & $40-2.40$ & $40-2.40$ & $40-2.40$ \\
\hline $\begin{array}{l}\text { Highest shell } \\
(\AA) \\
(\AA)\end{array}$ & $\begin{array}{l}2.49- \\
2.40\end{array}$ & $\begin{array}{l}2.43- \\
2.35\end{array}$ & $\begin{array}{l}2.49- \\
2.40\end{array}$ & $\begin{array}{l}2.49- \\
2.40\end{array}$ & $\begin{array}{l}2.49- \\
2.40\end{array}$ & $\begin{array}{l}2.49- \\
2.40\end{array}$ & $\begin{array}{l}2.49- \\
2.40\end{array}$ \\
\hline $\begin{array}{l}\text { No. of unique } \\
\text { reflections }\end{array}$ & 351,161 & 351,162 & 329,839 & 329,852 & 329,843 & 329,840 & 329,844 \\
\hline $\begin{array}{l}\text { Completeness } \\
\text { (\%) }\end{array}$ & 100.0 & 100 & 100 & 100 & 100 & 100 & 100 \\
\hline Multiplicity & $\begin{array}{l}913 \\
(629)\end{array}$ & $\begin{array}{l}494 \\
(339)\end{array}$ & $\begin{array}{l}159 \\
(109)\end{array}$ & $111(76)$ & $\begin{array}{l}249 \\
(172)\end{array}$ & $\begin{array}{l}271 \\
(187)\end{array}$ & $\begin{array}{l}235 \\
(162)\end{array}$ \\
\hline $\mathrm{R}_{\text {split }}{ }^{\ddagger}(\%)$ & $\begin{array}{l}3.9 \\
(38.0)\end{array}$ & $\begin{array}{l}5.7 \\
(56.5)\end{array}$ & $\begin{array}{l}8.1 \\
(60.7)\end{array}$ & $\begin{array}{l}10.8 \\
(76.6)\end{array}$ & $\begin{array}{l}6.7 \\
(53.3)\end{array}$ & $\begin{array}{l}7.3 \\
(56.4)\end{array}$ & $\begin{array}{l}8.4 \\
(63.8)\end{array}$ \\
\hline $\mathrm{CC}_{1 / 2} \S$ & $\begin{array}{l}0.999 \\
(0.78)\end{array}$ & $\begin{array}{l}0.999 \\
(0.60)\end{array}$ & $\begin{array}{l}0.996 \\
(0.610)\end{array}$ & $\begin{array}{l}0.994 \\
(0.452)\end{array}$ & $\begin{array}{l}0.998 \\
(0.706)\end{array}$ & $\begin{array}{l}0.997 \\
(0.643)\end{array}$ & $\begin{array}{l}0.997 \\
(0.540)\end{array}$ \\
\hline mean $\mathrm{I} \sigma(\mathrm{I})$ & $\begin{array}{l}74.1 \\
(2.8)\end{array}$ & $\begin{array}{l}56.8 \\
(2.0)\end{array}$ & $\begin{array}{l}36.9 \\
(1.8)\end{array}$ & $\begin{array}{l}27.1 \\
(1.4)\end{array}$ & $\begin{array}{l}43.1 \\
(2.1)\end{array}$ & $\begin{array}{l}40.2 \\
(2.0)\end{array}$ & $\begin{array}{l}37.0 \\
(1.8)\end{array}$ \\
\hline \multicolumn{8}{|l|}{ Refinement } \\
\hline $\begin{array}{l}R_{\text {work }} / R_{\text {free }} \\
(\%)\end{array}$ & $\begin{array}{l}0.170 / / \\
0.215\end{array}$ & $\begin{array}{l}0.163 / \\
0.221\end{array}$ & & & & & $\begin{array}{l}0.166 / / \\
0.233\end{array}$ \\
\hline Wilson $B\left(\AA^{2}\right)$ & 50.0 & 52.0 & & & & & 50.8 \\
\hline $\begin{array}{l}\text { Average B- } \\
\text { factor }\left(\AA^{2}\right)\end{array}$ & 64.0 & 68.6 & & & & & 63.8 \\
\hline Protein & 62.0 & 66.4 & & & & & 63.6 \\
\hline OEC & 47.3 & 49.9 & & & & & 47.5 \\
\hline
\end{tabular}




\begin{tabular}{|c|c|c|c|}
\hline Water & 63.0 & 68.9 & 65.6 \\
\hline $\begin{array}{l}\text { RMSD bond } \\
\text { length }(\AA)\end{array}$ & 0.008 & 0.008 & 0.009 \\
\hline $\begin{array}{l}\text { RMSD bond } \\
\text { angle (deg.) }\end{array}$ & 1.292 & 1.187 & 1.306 \\
\hline \multicolumn{4}{|c|}{$\begin{array}{l}\text { Ramachandran } \\
(\%)\end{array}$} \\
\hline Favored & 98.00 & 97.56 & 97.39 \\
\hline Allowed & 1.92 & 2.25 & 2.38 \\
\hline Outliers & 0.08 & 0.19 & 0.23 \\
\hline PDB code & NA & 7CJI & 7CJJ \\
\hline
\end{tabular}

Values in parenthesis are those of the highest resolution shell.

Table 2. Interatomic distances of the OEC and their comparisons between different structures.

\begin{tabular}{|c|c|c|c|c|c|c|}
\hline & \multicolumn{2}{|c|}{ The present study (RT) } & \multicolumn{2}{|c|}{ Suga et al. $(100 \mathrm{~K})^{8}$} & \multicolumn{2}{|c|}{ Kern et al. (RT $)^{9}$} \\
\hline & $\mathrm{S}_{1}$ & $\mathrm{~S}_{2}$ & $\mathrm{~S}_{1}$ & $\mathrm{~S}_{2}$ & $\mathrm{~S}_{1}$ & $\mathrm{~S}_{2}$ \\
\hline Mn1-Mn2 & 2.65 & 2.63 & 2.60 & 2.68 & 2.78 & 2.81 \\
\hline Mn1-Mn3 & 3.16 & 3.19 & 3.16 & 3.21 & 3.25 & 3.26 \\
\hline Mn1-Mn4 & 4.92 & 4.90 & 4.97 & 4.90 & 4.86 & 4.86 \\
\hline Mn2-Mn3 & 2.77 & 2.72 & 2.72 & 2.75 & 2.85 & 2.84 \\
\hline Mn2-Mn4 & 5.27 & 5.19 & 5.27 & 5.20 & 5.21 & 5.24 \\
\hline Mn3-Mn4 & 2.83 & 2.78 & 2.89 & 2.76 & 2.74 & 2.74 \\
\hline $\mathrm{Mn} 1-\mathrm{Ca}$ & 3.51 & 3.53 & 3.61 & 3.51 & 3.43 & 3.42 \\
\hline $\mathrm{Mn} 2-\mathrm{Ca}$ & 3.43 & 3.44 & 3.42 & 3.40 & 3.38 & 3.41 \\
\hline Mn3-Ca & 3.46 & 3.59 & 3.40 & 3.46 & 3.51 & 3.52 \\
\hline Mn4-Ca & 3.88 & 4.04 & 3.76 & 3.90 & 3.83 & 3.90 \\
\hline
\end{tabular}

Figures 
Fig. 1
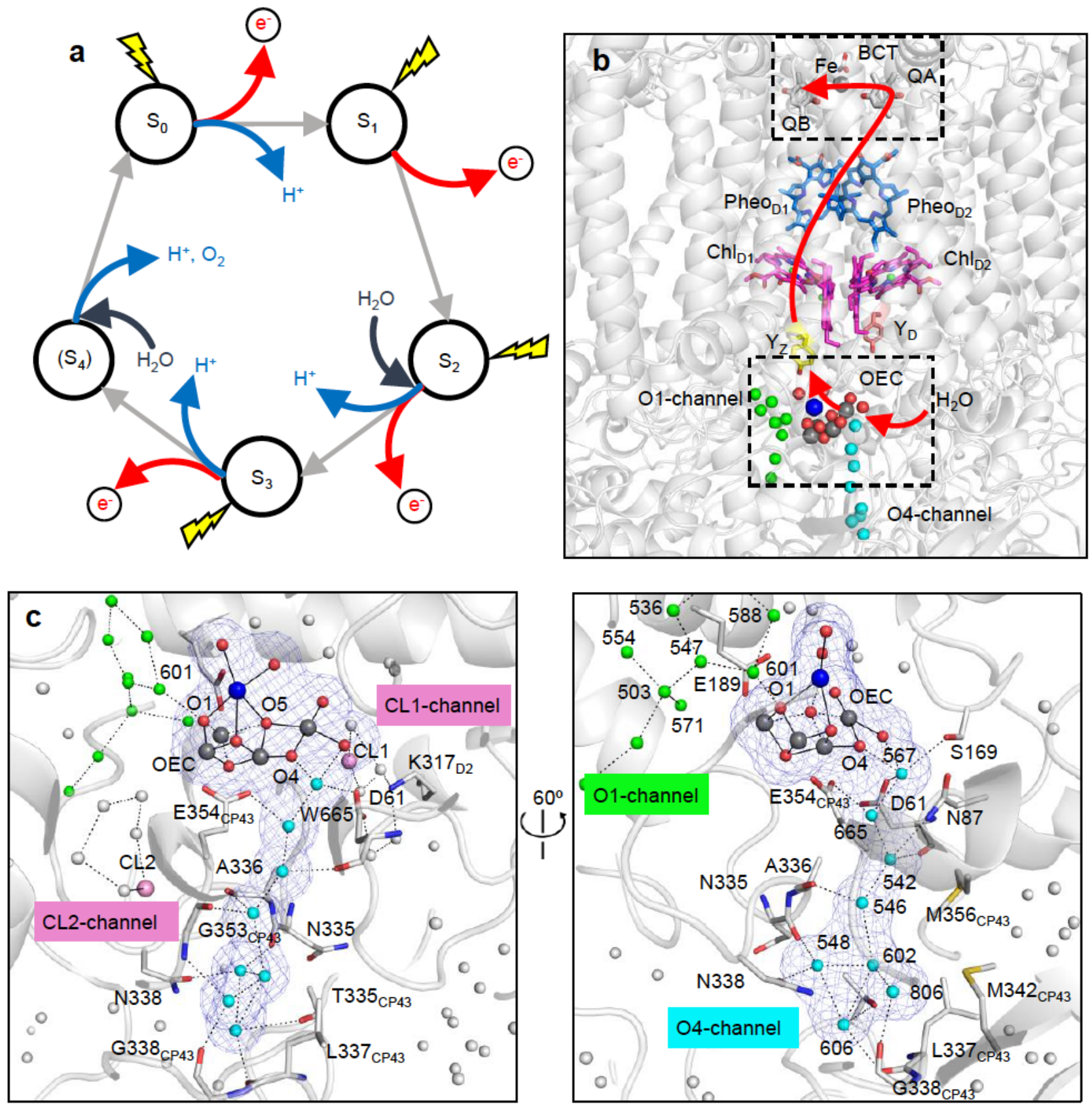

\section{Figure 1}

Si-state cycle for the water oxidation reaction and water channels in PSII. a Si-state cycle of the wateroxidation reaction of OEC. b Electron transfer chain of PSII. A flow of electron is indicated by a red line, and the regions around the OEC, QB and the non-heme iron are boxed with black dashed lines. c Enlarged views of the boxed region around the OEC shown in b. Water molecules in the 01-channel and 04-channel 
are shown as green and cyan spheres, respectively. The light blue mesh shows the radius of atoms of the OEC and water molecules in the 04-channel.

\section{Fig. 2}
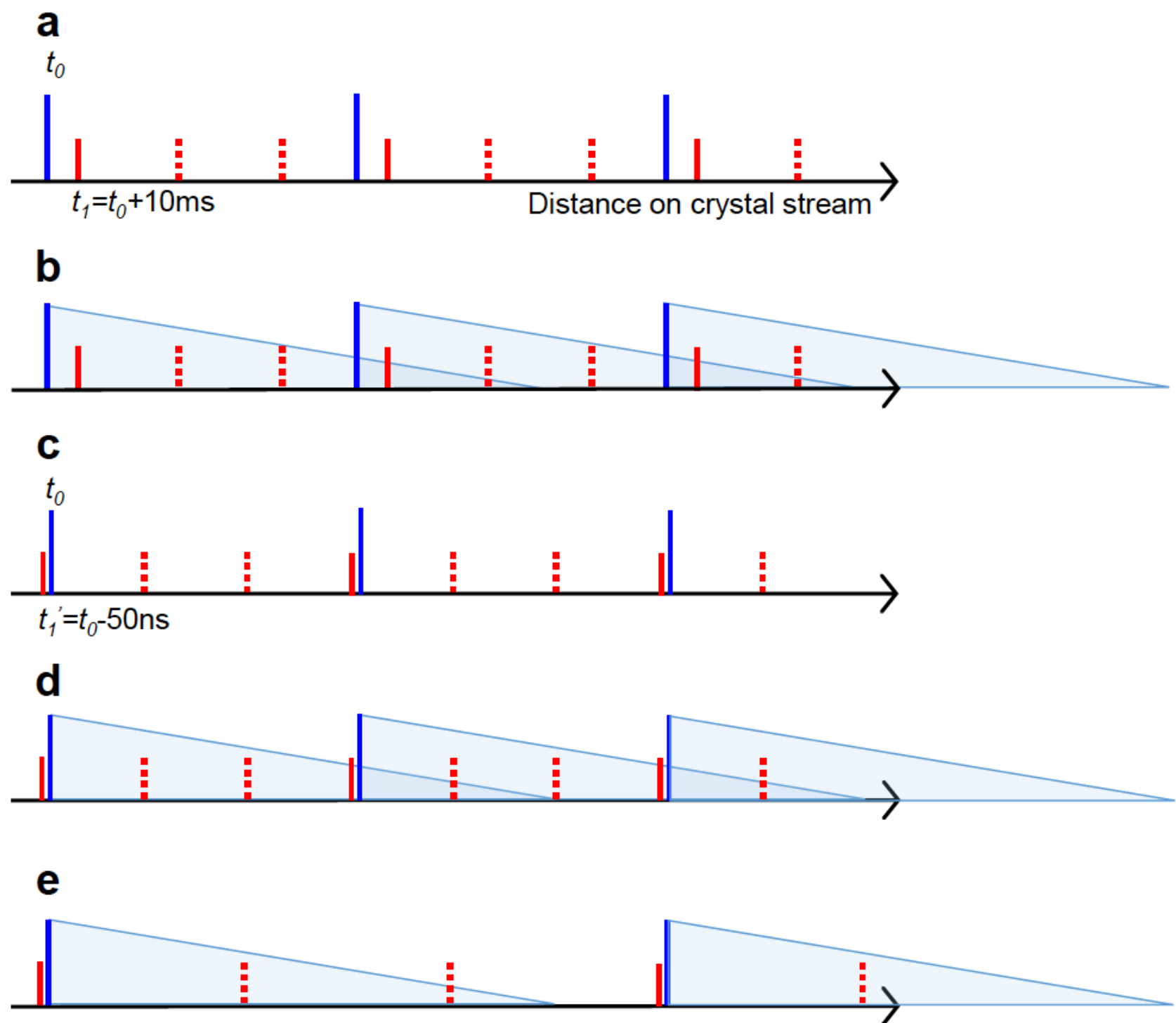

Pump laser $(10 \mathrm{~Hz})-\mathrm{XFEL}(30 \mathrm{~Hz}) \square$ Excitation region

\section{Figure 2}

Schematic representation of the timing of the pump lasers and XFEL pulses. a, c Relative timing of the pump lasers and XFEL pulses with $\Delta t$ of $10 \mathrm{~ms}$ (a) and $\Delta t$ of -50 ns (c). b, d, e Schematic representations of the boundaries where the pump lasers reaching at a slower flow rate with $\Delta t$ of $10 \mathrm{~ms}$ (b) or with $\Delta t$ of $-50 \mathrm{~ns}(\mathrm{~d})$, and that at a faster flow rate with $\Delta \mathrm{t}$ of $-50 \mathrm{~ns}(\mathrm{e})$. Note that the region exposed to XFEL pulses 
interact with multiple pump lasers when a slower flow rate was employed (b, d). XFEL pulses that were not recorded for the "light" datasets are shown as dash lines.

\section{Fig. 3}
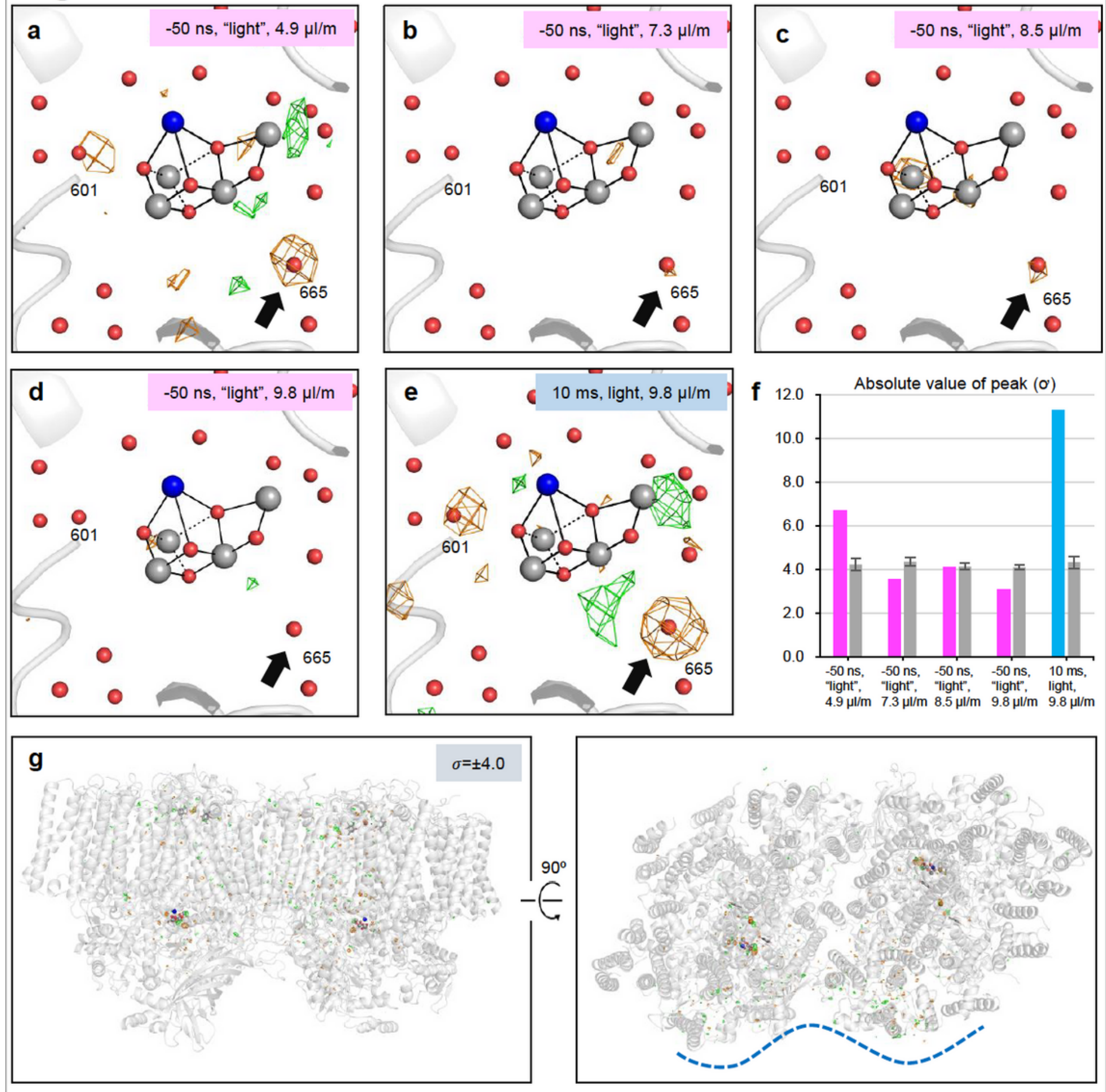

\section{Figure 3}

Light-induced structural changes in PSII observed at different flow rates. a-e The S1 state structure superimposed with Fobs(light) - Fobs(dark) isomorphous difference Fourier map contoured at $+4.0 \sigma$ (green) and $-4.0 \sigma$ (orange) calculated with the "light" datasets obtained under conditions of (a) $-50 \mathrm{ns,}$ 
"light", $4.9 \mu \mathrm{l} / \mathrm{m}$ flow rate, (b) -50 ns, "light", $7.3 \mu \mathrm{l} / \mathrm{m}$, (c) -50 ns, "light", $8.5 \mu \mathrm{l} / \mathrm{m}$, (d) -50 ns, "light", 9.8 $\mu \mathrm{l} / \mathrm{m}$, and (e) $10 \mathrm{~ms}$, light, $9.8 \mu \mathrm{l} / \mathrm{m}$. The changes in W665 were indicated by black arrows. $\mathrm{f}$ Average peak heights of the difference map at the position of W665 calculated from two PSII monomers and maximum noises. Maximum noise levels with the error bar were calculated from five strongest noise peaks observed in the outside of PSII protein complex and shown in gray. $g$ The overall PSII structure superposed with the difference map calculated with the dataset of $10 \mathrm{~ms}$, light, $9.8 \mu \mathrm{l} / \mathrm{m}$ at the same contour levels and color scheme as (e). The dimer interface where the minor structural changes distributed is indicated by a blue dashed line.

\section{Fig. 4}
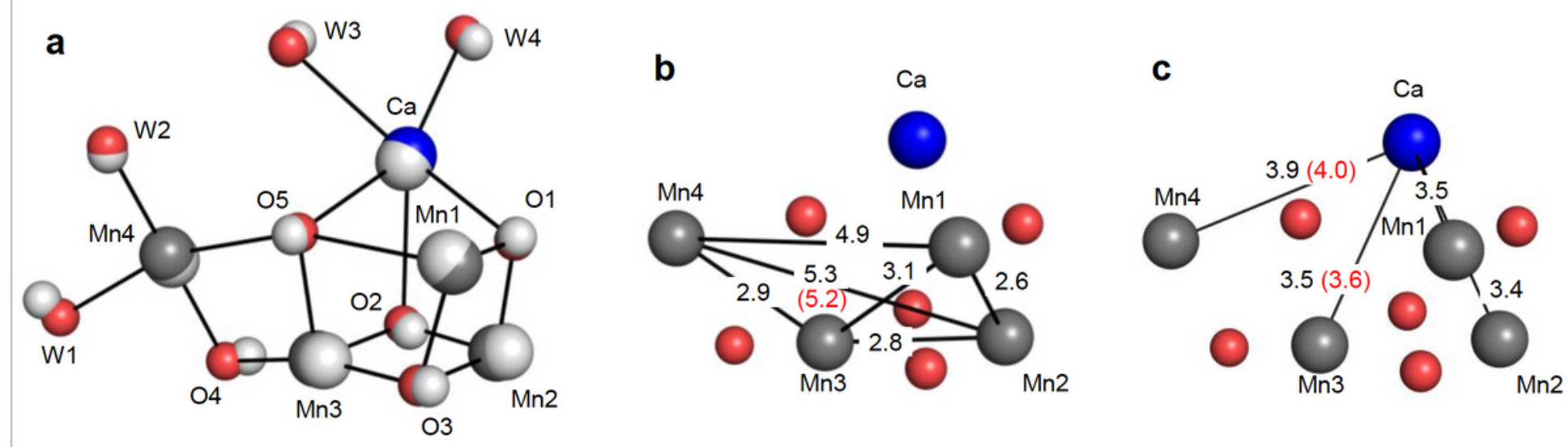

Figure 4

Structures of OEC in the S1 and S2 states. a-c OEC structures in the S1 and S2 states are shown in grey and colored atoms, respectively. Color codes: blue for calcium; cyan for manganese; red for oxygen. The color codes for the OEC are kept in all figures unless otherwise noted. In b, c, interatomic distances are shown in $\AA$, with the numbers in black for S1 and red for S2, respectively. The distances in the S2 state were shown only when they are changed more than $0.1 \AA$ compared with the corresponding distances in the $\mathrm{S} 1$ state. 
Fig. 5
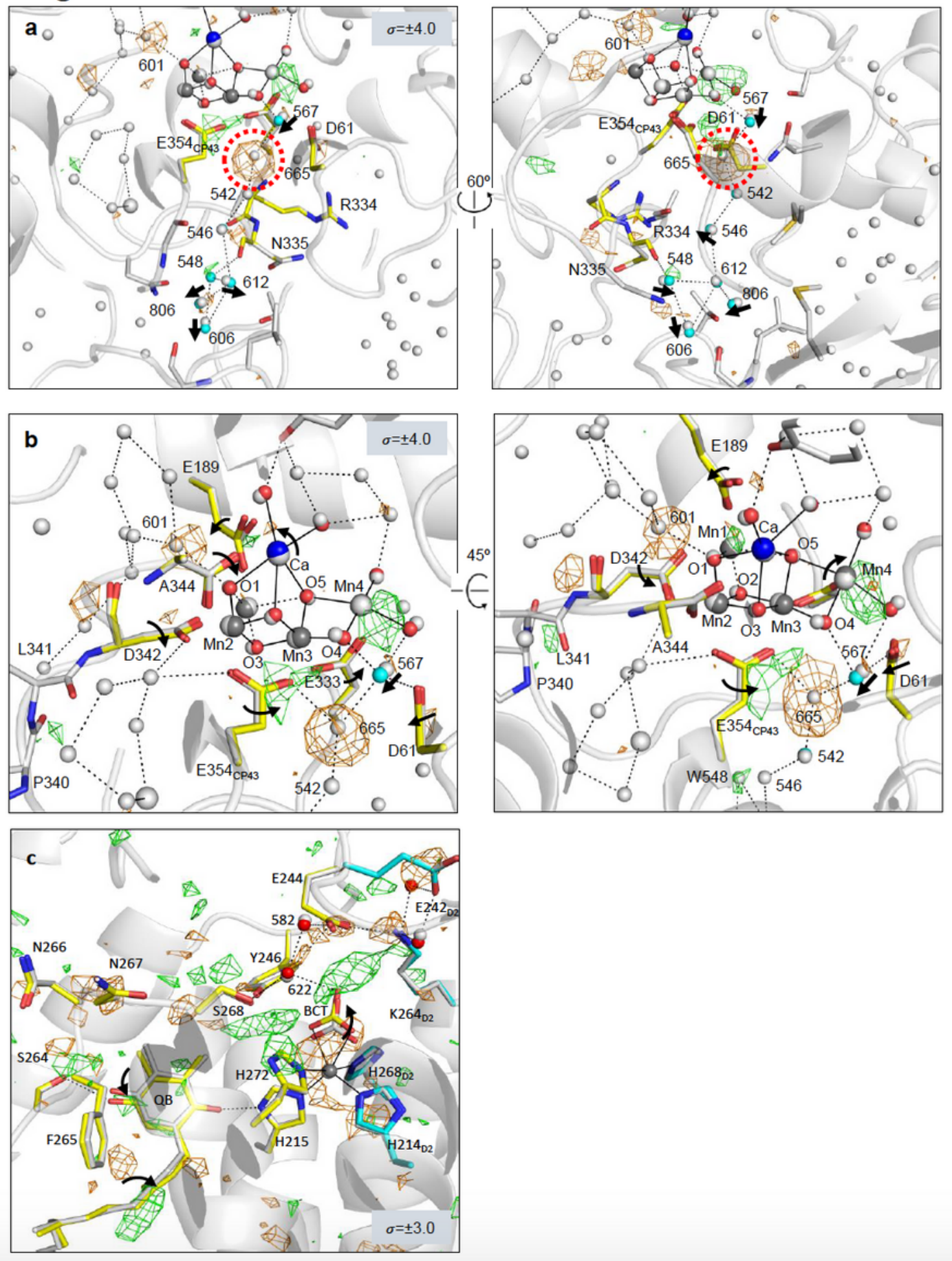

\section{Figure 5}

Structural changes occurred during the S1-to-S2 transition. The structures of PSII in the S1 (gray) and S2 state (colored) superimposed with isomorphous difference Fourier map in the regions of the 04-channel (a), the OEC (b), and QB site (c). The difference Fourier map was contoured at $\pm 4 \sigma(a, b)$ and $\pm 3 \sigma(c)$ in the same color as those in Fig. 3. H-bond networks of waters are represented by a black dot lines, and the structural changes are indicated by black arrows. W665 is encircled with a red dashed circle in panel a. 


\section{Fig. 6}

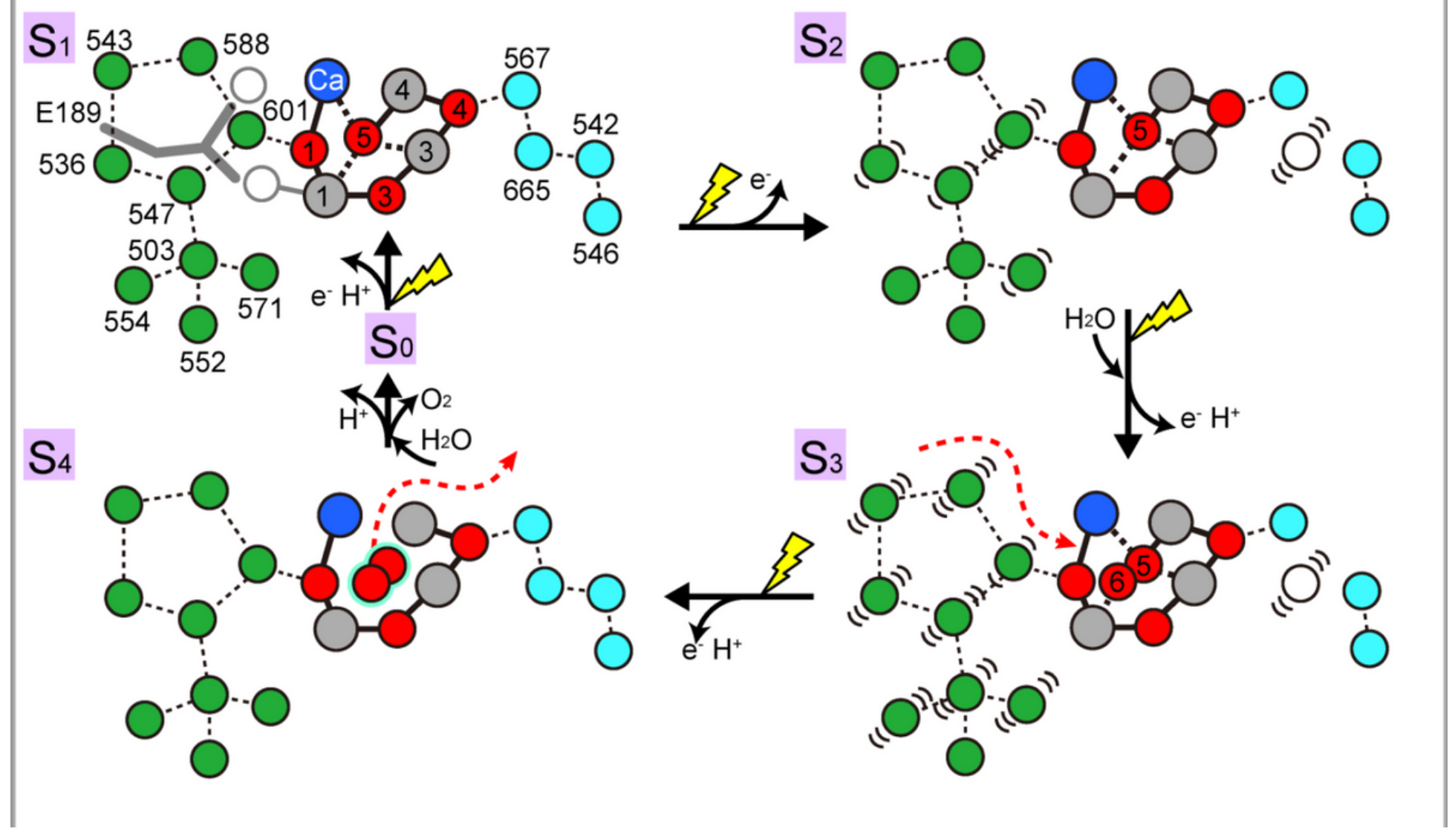

Figure 6

Structural changes in the water networks in the 01 and 04 channels during the water oxidation reaction. Structural changes in the OEC and water molecules found in the present and previous studies are summarized. Red and Gray spheres with numbers in the OEC were oxygen and manganese atoms, respectively, and the $\mathrm{Mn} 2$ and $\mathrm{O} 2$ atoms were omitted from the figure for clarity. 